\title{
Impairment and perseveration in delayed tasks due to bilateral lesions of the caudate nucleus in rats
}

\author{
WILLIAM L. MIKULAS ${ }^{1}$ AND ROBERT L. ISAACSON \\ UNIVERSITY OF MICHIGAN
}

\begin{abstract}
Rats with bilateral lesions in the caudate nucleus were found to exhibit perseverative response tendencies which interfere with performance on a delayed response task. Evidence was obtained which suggests that the caudate lesioned Ss had "expectancies" about the correct response to be made despite their initial failure to express them in the testing situation.
\end{abstract}

\section{Introduction}

Bilateral lesions in the caudate nucleus have been shown to cause a deficit in the acquisition and retention of spatial alternation in rats (Chorover \& Gross, 1963), delayed alternation in monkeys (Battig et al, 1960; Rosvold \& Delgado, 1956; Rosvold et al, 1958), and delayed responses in monkeys (Battig et al, 1960). The type of errors the animals in the above studies made appears to reflect an inability to inhibit a dominant pattern of responding. It is this aspect of behavior which is investigated in the present study.

\section{Subjects}

Twenty male albino rats weighing 225-250 gm at the beginning of the experiment were divided into three groups $(\mathrm{N}, \mathrm{C}, \mathrm{O})$. Group $\mathrm{N}$ consisted of eight normal rats; group $\mathrm{C}$ consisted of eight rats which received bilateral radio-frequency lesions of the caudate nucleus before training; and group $\mathrm{O}$ consisted of four rats (one of which died from infection during training) which were subjected to the same operative procedures as group $\mathrm{C}$ except no current was passed through the electrodes. Verification of the lesions was made histologically following the experiment. In general the lesions involved about $15 \%$ of the area of the caudate nucleus at a plane $1.5 \mathrm{~mm}$ anterior to bregma when the animal was in a Kreig-Johnson stereotaxic instrument.

\section{Apparatus}

Delayed response ability was studied in two situations: a 2-choice and a 4-choice task. Half of the Ss of groups $\mathrm{N}$ and $\mathrm{C}$ were run in the 2-choice apparatus; the other half of each group was run in the 4-choice apparatus. Group $O$ was run only in the 4-choice situation. Each apparatus consisted of a start box 7 in long, 5 in wide, and 4 in high with a Plexiglas door. Panels of goal doors were visible from the start box. The goal doors were 2 in square and separated from any adjacent door or wall by 1 in. In the 4-choice apparatus the goal doors were 10 in from the start box; while in the 2-choice they were 30 in away. In the latter a runway 5 in wide, 4 in high, and 24 in long was placed between the the start box and the goal box. In the 2-choice task running speeds were measured over a 22 in section of the runway.

\section{Procedure}

After the rats were adapted to their respective apparatus and to the deprivation schedule, they were given 20 trials a day, every other day, under $46 \mathrm{hr}$. water deprivation. A trial consisted of $\mathrm{S}$ being placed in the start box and a subsequent $30 \mathrm{sec}$. period during which time one of the goal doors was opened with an illuminated 100 watt bulb behind it. This was followed by a $10 \mathrm{sec}$. "delay period" in which the goal door was closed and the light extinguished. After this delay the start box door was opened. A small water dish, $1 / 4$ in high and 1-1/4 in in circumference, was behind the door that had been signaled. The Ss had to only touch a door for it to open. A correction procedure was used: the Ss remained in the apparatus until they found the water. After reaching the water they were allowed $5 \mathrm{sec}$. of drinking time. In the 2-choice situation the door indicating the water was randomly determined across trials. In the 4-choice situation the selection of the "rewarded door" was made randomly among the three doors not containing water on the previous trial. One-hundred trials were given in the 2-choice task; 200 trials were given in the 4-choice task.

\section{Results}

4-choice apparatus. The mean number of trials to reach a criterion of approaching the correct door first in 4 out of 5 trials for Ss of group $\mathrm{N}$ was 49.25. None of the rats of group $\mathrm{C}$ reached this criterion. If a "dominant response" is defined as first approaching that door which had been approached first on most trials over all days, the mean number of such dominant responses for the last 120 trials for the Ss of group $\mathrm{N}$ was 47.5 while the mean number of dominant responses for the Ss of group C was $104.5(t=7.85$, $\mathrm{df}=6, \mathrm{p}<.001)$. The number of dominant responses per day across the testing period is given for the separate Ss of the different groups in Fig. 1. Qualitatively, the dominant response for each rat of group $\mathrm{N}$ was approaching one of the two middle doors, while the dominant response for each of the rats of group $\mathrm{C}$ was approaching one of the two extreme doors. The two rats of group $O$ that showed some damage to the 
caudate nucleus behaved exactly as the rats of group $C$, while the other rat of group $O$ behaved like the rats of group $\mathrm{N}$.

At the end of the 200 trials the rats of group $C$ were given three additional trials with two procedural changes, (1) no water was placed behind any of the doors, and (2) the rat had to push the doors completely open. Every animal with caudate damage exhibited the same pattern of behavior: although the animal did not go first to the door which had been signaled by the light (usually the dominant response was made), the signaled door was the only one actually pushed open, and it was always pushed open. The animals appeared frustrated and somewhat more active in the start box during these trials.

2-choice apparatus. All Ss failed to exhibit efficient

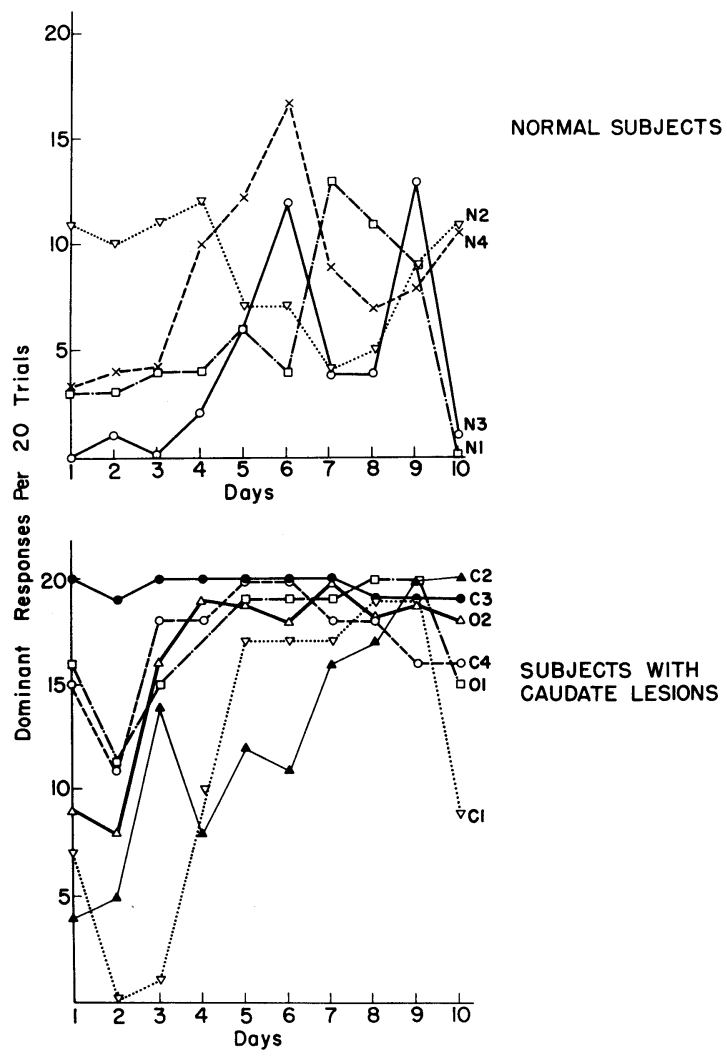

Fig. 1. behavior in the 2-choice delayed response task. The animals tended to persist making their dominant response. For group $\mathrm{N}$ the mean number of dominant responses for the 100 trials was 84.75 while the mean for group $C$ was 92.25 . This difference is not statistically significant. The mean running time for Ss of group $\mathrm{N}$ was $.89 \mathrm{sec}$. This was not significantly higher than that for group $\mathrm{C}(.81 \mathrm{sec}$.$) . There was$ some tendency, although it was not significant, for animals from both groups to run faster on trials when the light signaling the water was presented on the same side as the dominant response.

\section{Diseussion}

In the rat, as in the monkey, bilateral lesions in the caudate nucleus result in a deficit to perform the delayed response task. The extra trials given animals with caudate destruction in the 4-choice situation suggest that although the rats perseverated approach responses to certain doors, they have some "expectancies" concerning the door behind which water can be found. To the extent that running speed is a measure of motivational changes, the difference between normal animals and those with caudate destruction is due to other variables. Observations made of Ss in the two delayed response situations suggests that the difference between them is that when the goal doors are farther from the start box, as in the 2-choice task, the rats do not sufficiently attend to the dues presented during the $30 \mathrm{sec}$. retention period, and consequently cannot solve the problem effectively.

\section{References}

Battig, K., Rosvold, H. E., \& Mishkin, M. Comparisons of the effects of frontal and caudate lesions on delayed response and alternation in monkeys. J. comp. physiol. Psychol., 1960, 53, 400404.

Chorover, S. L., \& Gross, C. G. Caudate nucleus lesions: behavioral effects in the rat. Science, 1963, 141, 826-827.

Rosvold, R. E., \& Delgado, J. M. R. The effect on delayed-alternation test performance of stimulating or destroying electrically structures within the frontal lobes of the monkey brain. J. comp. physiol. Psychol., 1956, 49, 365-372.

Rosvold, H. E., Mishkin, M., \& Szwarcbart, M. K. Effects of subcortical lesions in monkeys on visual-discrimination and singlealternation performance. J. comp. physiol. Psychol., 1958, 51, 437-444.

\section{Note}

1. The first author and the study were supported in part by a USPHS fellowship (1-F1-MH-29, 114-01) and in part by a grant from the Surgeon General, U. S. Army (DA-MD-49-193-65-G144) to R. L. Isaacson. 